\title{
Synthesis and flocculation characteristics of cationic modified corncob: A novel polymeric flocculant
}

\author{
Yanhua Pang $^{1^{*}}$, Yongsheng Ding ${ }^{2}$, Jie Chen $^{3}$, Weimin Gong ${ }^{3}$ \\ ${ }^{1}$ Center of Food Inspection, Liaoning Entry-Exit Inspection and Quarantine Bureau, Dalian, China; \\ *Corresponding Author: cindy_gl@eyou.com \\ ${ }^{2}$ College of Ocean Environment and Engineering, Shanghai Maritime University, Shanghai, China \\ ${ }^{3}$ College of Environmental Science and Engineering, Dalian Maritime University, Dalian, China
}

Received July 2013

\begin{abstract}
A novel organic polymeric flocculant was synthesized by grafting cationic etherifying monomer (3-chloro-2-hydroxypropyl) trimethyl ammonium chloride (CHPTAC) onto the backbone of corncob powder (CP, $\Phi \leq \mathbf{3 0} \mu \mathrm{m})$. The synthetic reaction between CP and CHPTAC was initiated by hydroxyl radical made from Fenton reagent $\left(\mathrm{H}_{2} \mathrm{O}_{2}-\mathrm{FeSO}_{4}\right)$. The alkalization process and synthetic reaction conditions were optimized by varying several parameters affecting grafting efficiency, such as $\mathrm{NaOH}$ dose, monomer concentration, reaction temperature and time and distilled water dose. The synthesized cationic flocculant was characterized by elemental analysis, Fourier-transform infrared spectrometer and scanning electron microscope techniques. It was concluded that the backbone of $\mathrm{CP}$ have been grafted cationic etherifying monomer. The flocculation characteristics in $0.25 \%(w / v)$ kaolin suspensions was compared with some of the commercial flocculants available in markets, and the results demonstrated the synthesized cationic flocculation has superiority as a novel flocculant.
\end{abstract}

Keywords: Flocculation; Corncob; Polymeric Flocculant; CHPTAC

\section{INTRODUCTION}

Flocculation [1-3] is a process of bringing together smaller particles to form larger particles, and settling of colloidal particles from stable suspensions caused by the addition of chemicals known as flocculants in minute quantities. It is well known that the use of organic and inorganic flocculants can improve the efficiency of solid/liquid separation in a wide range of papermaking, wastewater treatment and mineral processing industries [4-7]. The inorganic flocculants, which are mainly based on hydrolyzable salts of aluminum, cannot be removed easily during treatment, and the residue in water can cause some health problems [8]. Natural and synthetic polymeric flocculants, which are able to destabilize colloidal suspensions, have been found wide application as flocculating agents in the past decade. Water-soluble synthetic polymers [9-11] have a disadvantage of non-biodegradability and cost-effective. Thus, the demand for effective, cheap and environmentally friendly natural flocculants for wastewater treatment is increasing.

With the characteristics of nontoxic and biodegradable, the so-called "green flocculants" such as starch [12,13], amylopectin [14], alginic acid [15], guar gum [16], and so forth, have been paid much attention. The chemical and physical properties of the natural polymers can be modified by grafting a synthetic polymer onto the backbone of natural polymers. For highly negatively charged colloidal particles, cationic polymers are more used as flocculating agents to remove finely divided solids from aqueous suspension [17].

The natural corncob powder (CP), mainly composed of cellulose, lignose and pentosan, has abundant output in China. Composed of much hydroxyl radicals, CP may be grafting by cationic polymers and perform efficient flocculation characteristics. In view of several authors' earlier findings, CP was chosen as the base polymer grafting by a quaternary ammonium compound [18]. However, it has not been much studied as flocculating agent for wastewater treatment.

Highly charged cationic polymers such as polyamines and polyimines are costly. Therefore, it has been attempted to synthesize a cationic quaternary ammonium salt (3-chloro-2-hydroxypropyl) trimethyl ammonium chloride (CHPTAC). The present work aims to explore the feasibility of grafting flocculation (DXSL-I) of CP and CHPTAC, illustrate its characteristics by using elemental analysis, Fourier-transform infrared (FTIR) and scan- 
ning electron microscope (SEM) and evaluate its flocculation performance. The reaction parameters affecting grafting efficiency, such as $\mathrm{NaOH}$ dose, monomer concentration, reaction temperature and time and distilled water dose were also investigated.

\section{EXPERIMENTAL}

\subsection{Materials}

Corncob powder (CP, (థ区 $30 \mathrm{~mm})$, obtained from Dalian Farm Product Processing Plant, was dried at $100^{\circ} \mathrm{C}$ for $4 \mathrm{~h}$ before use. Triethylamine, Epoxy chloropropane, all purchased from Shanghai Reagent Company, China, were of analytical reagent grade. Aluminum chlorate and Polyacrylamide are used as commercial flocculants for comparison test. All the reagents were used without further purification. Kaolin clay $(\Phi \leq 2 \mathrm{~mm})$ was purchased from Zhonglong Kaolin Ltd., China.

\subsection{Preparation of Cationic Monomer}

The reaction conditions were established according to our previous experience [18]. Epoxy chloropropane (20 $\mathrm{ml}$ ) was mixed with excessive triethylamine in a sealed flask with constant stirring. The reaction was allowed to continue for $3 \mathrm{~h}$ at a reaction temperature of $0^{\circ} \mathrm{C}-5^{\circ} \mathrm{C}$, after which the sample was settled at ice bath for $2 \mathrm{~h}$. The content of upper solution, in which was the cationic monomer (3-chloro-2-hydroxypropyl) trimethyl ammonium chloride (CHPTAC), can be determined by using $\mathrm{Ag}^{+}$solution. The quaternary ammonium monomer was decomposed easily under daylight or high temperature. Therefore, the use of instant prepared monomer was suggested. The reaction of quaternary ammonium group preparation was shown as followed:

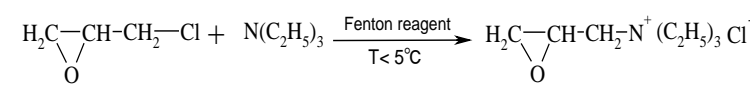

\subsection{Synthesis of Cationic Flocculant DXSL-I}

Corncob powder can be modified by incorporating a cationic monomer (3-chloro-2-hydroxypropyl) trimethyl ammonium chloride onto the backbone of the polysaccharide. The details of the synthesis and the reaction conditions are as follows.

Corncob powder (2.0 g) was dissolved in distilled water $(8.0 \mathrm{ml})$ at room temperature. As alkaline medium is essential to carry out the reaction, $0.002 \mathrm{~g} \mathrm{NaCl}$ and 0.6 g $\mathrm{NaOH}$ were added to it. The reaction solution was alkalized for $60 \mathrm{~min}$ at $40^{\circ} \mathrm{C}-50^{\circ} \mathrm{C}$, followed by adding Fenton reagent $\left(\mathrm{H}_{2} \mathrm{O}_{2}\right.$ and $\mathrm{Fe}^{2+}$ were $0.8 \%-1.2 \%$ and $0.005 \%$ of CP mass, respectively) into the solution to initiate the reaction for 30 - $90 \mathrm{~s}$. Reaction was then continued for $3 \mathrm{~h}$ with excessive CHPTAC at $50^{\circ} \mathrm{C}$. The solution was thereafter cooled to room temperature, and the copolymer was precipitated by centrifugation. The residue was washed with distilled water several times until its $\mathrm{pH}$ reached 7 - 8 and there was not CHPTAC in the filtrate checked with $\mathrm{Ag}^{+}$solution. After washing, it was dried in a vacuum oven.

\subsection{Characterization of Cationic Flocculant DXSL-I}

\subsubsection{Elemental Analysis}

Elemental analysis of the cationic flocculant DXSL-I, CP and CHPTAC was undertaken with a LiquiTOC elemental analyzer (Elementar Analysensysteme GmbH, German). The estimation of only three elements, that is carbon, hydrogen and nitrogen, was undertaken.

\subsubsection{FTIR Spectroscopy}

A 500 FTIR Spectrophotometer (Nicolet, USA) was used and the potassium bromide $(\mathrm{KBr})$ pellet method was used for FTIR study. The FTIR spectrum of cationic flocculation DXSL-I, alkalized CP and CP were collected separately.

\subsubsection{Scanning Electron Microscopy (SEM)}

The small granules left after the pulverized graft copolymers and CP were sieved, and were subjected to SEM study. The samples were gold-coated, and a magnification of 2000 times was obtained. A Philips XL-30 Scanning Electro-Microscope (Holland) was used for SEM study.

\subsection{Flocculation Test}

Flocculation capacity of DXSL-I and other commercial flocculants were evaluated using $0.25 \%(\mathrm{w} / \mathrm{v})$ of kaolin suspensions. After addition of flocculants solution (80 - $100 \mathrm{ml}$ ), mixtures were mechanically stirred at a constant speed of $200 \mathrm{rpm}$ for $2 \mathrm{~min}$, followed by a slow stirring at $40 \mathrm{rpm}$ for $10 \mathrm{~min}$. Thereafter, the sample was left to settle for $5 \mathrm{~min}$. At the end of the settling, $10 \mathrm{ml}$ of the supernatant fluid was taken from the beaker surface, and its transmittance was measured at a wavelength of $610 \mathrm{~nm}$ by using JASCO V-500 Spectrometer (Japan).

\section{RESULTS AND DISCUSSION}

\subsection{Synthesis Mechanism}

Corncob, mainly consisted of polysaccharide, was a natural polymer. There were many - $\mathrm{OH}$ groups on its microparticle's surface [19]. Cationic modification was based on these radicals. The synthetic reactions were etherifying processes as shown in Eqs.2 and 3.

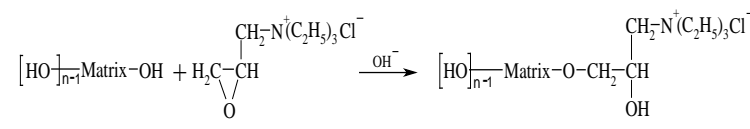




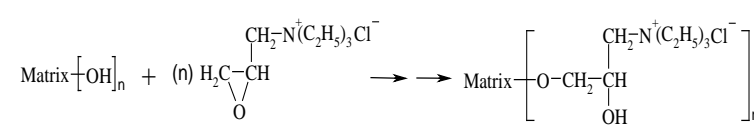

Reactions were theoretically divided into several steps, including the free radical chain reaction and ion reaction $[20,21]$. The formation of free $\mathrm{OH}$ groups could be expressed as followed equations:

$$
\begin{gathered}
\mathrm{Fe}^{2+}+\mathrm{H}_{2} \mathrm{O}_{2} \longrightarrow \mathrm{Fe}^{3+}+\mathrm{HO} \cdot{ }^{+} \mathrm{OH}^{-} \\
\text {Matrix- } \mathrm{OH}+\mathrm{HO} \cdot \longrightarrow \text { Matrix-O* }+\mathrm{H}_{2} \mathrm{O}
\end{gathered}
$$

The synthetic reaction was actually an electro-nucleophilic process as shown below:

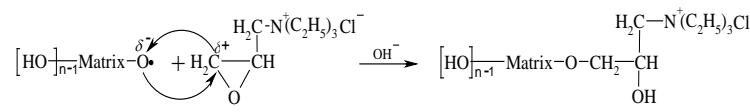

Some possible unwished negative reactions may happen as indicated from Eqs.7 to 10, where included free radical transfers and exterminations, as well as the splitup of etherified monomer by hydrolyzation.

$$
\begin{aligned}
& \mathrm{HO} * \mathrm{H}_{2} \mathrm{O}_{2} \longrightarrow \mathrm{H}_{2} \mathrm{O}+\mathrm{HOO} \text {. } \\
& \text { HOO* }+\mathrm{H}_{2} \mathrm{O}_{2} \longrightarrow \mathrm{H}_{2} \mathrm{O}+\mathrm{HO}+\mathrm{O}_{2} \\
& \mathrm{Fe}^{2+}+\mathrm{HO} \cdot \longrightarrow \mathrm{Fe}^{3+}+\mathrm{HO}^{-} \\
& \begin{array}{ccc}
\text { Matrix }-\mathrm{O}-\mathrm{CH}_{2}-\underset{!}{\mathrm{CH}}-\mathrm{CH}_{2}-\mathrm{N}^{+}(\mathrm{R})_{3} \mathrm{Cl}^{-}+\mathrm{H}_{2} \mathrm{O} \stackrel{\mathrm{HO}^{-}}{\longrightarrow} \underset{\mathrm{OH}}{\longrightarrow} \begin{array}{l}
\mathrm{H}_{2} \mathrm{C}-\mathrm{CH}-\mathrm{CH}_{2}-\mathrm{N}^{+}(\mathrm{R})_{3} \mathrm{Cl} \\
\mathrm{OH} \mathrm{OH}
\end{array} \\
\end{array}
\end{aligned}
$$

\subsection{Synthesis Conditions and Influence Factors}

\subsubsection{NaOH Dosage, Alkalizing Temperature and Time}

In order to evaluate the effect of $\mathrm{NaOH}$ dose on the grafting of CHPTAC onto CP, a set of experiments were carried out, in which the dose was changed from $0.10 \mathrm{~g}$ to $6.00 \mathrm{~g}$, while all the other parameters were kept unchanged. The results showed an increase in the grafting percentage with the increase in $\mathrm{NaOH}$ dose. However, beyond a value of $0.6 \mathrm{~g}$, a significant decrease in grafting percentage was observed. According to synthesis reaction (Eq.2), the low dose $\mathrm{OH}$ - was helpful to change $\mathrm{OH}$ group into ionic oxygen, of which the nucleophilic capacity was strengthened consumedly. However, overdose of $\mathrm{NaOH}$ could make the epoxy ring broken up and accelerate the quaternary ammonium radical decomposed, resulting in grafting efficiency reduced. The similar results were found after a series of experiments about alkalization conditions. There is also an increase in the grafting percentage with the alkalizing temperature and time, but a reduction occurred with the alkalizing temperature raised and time prolonged. The density of free radicals was less, resulting in reduction of grafting efficiency with the alkalizing temperature and time increased. After the optimization experiments, it was obtained the $\mathrm{NaOH}$ dosage is $0.6 \mathrm{~g}$, alkalizing temperature is $40^{\circ} \mathrm{C}-50^{\circ} \mathrm{C}$ and alkalization time is $60 \mathrm{~min}$.

\subsubsection{Monomer Concentration}

As shown in Figure 1, the grafting percentage significantly increased with increasing monomer concentration. The presence of a high concentration of CHPTAC in the medium provided a greater availability of CHPTAC molecules to react with the CP macroradicals, leading to a higher synthesis percentage. However, overdose of monomer costs highly and unbeneficial.

\subsubsection{Orthogonal Experiment}

In addition to monomer concentration, distilled water medium, synthesis temperature and time were also the influence factors governing the grafting efficiency. Therefore, a series of experiments were carried out by orthogonal method to optimize the reaction conditions affecting flocculation efficiency. Taking CP (2.0 g), we examined the influence factors including the reaction temperature $\left(30^{\circ} \mathrm{C}-60^{\circ} \mathrm{C}\right)$, reaction time $(2-5 \mathrm{~h})$ and distilled water $(4-16 \mathrm{ml})$, respectively. The final optimized condition was obtained as follows: synthesis temperature $50^{\circ} \mathrm{C}$, synthesis time $3.0 \mathrm{~h}$, and distilled water $8.0 \mathrm{ml}$. The orthogonal experimental parameters were shown in Table 1.

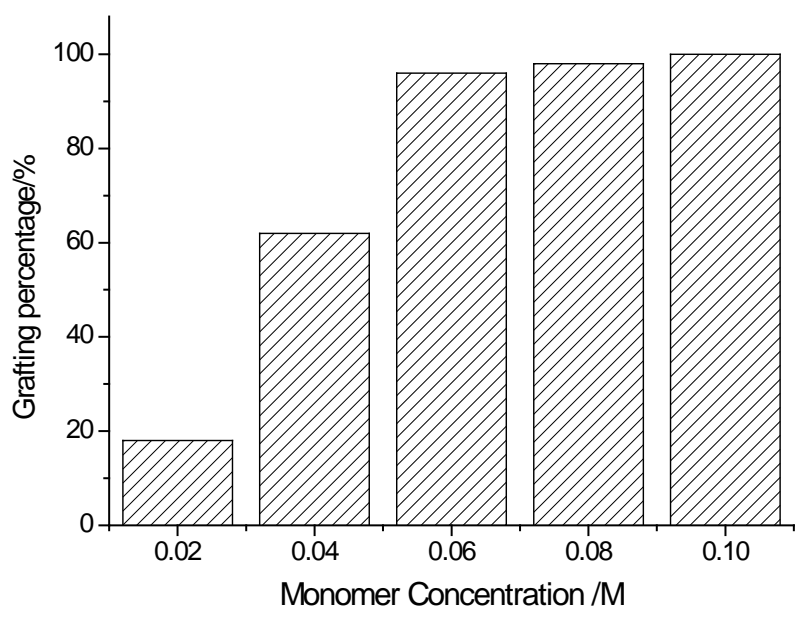

Figure 1. Effect of monomer concentration on grafting percentage (CP dosage: $2.0 \mathrm{~g})$.

Table 1. The orthogonal experimental parameters.

\begin{tabular}{cccc}
\hline No. & Reaction temperature $\left({ }^{\circ} \mathrm{C}\right)$ & Reaction time $(\mathrm{h})$ & Water $(\mathrm{ml})$ \\
\hline 1 & 30 & 2 & 4 \\
2 & 40 & 3 & 8 \\
3 & 50 & 4 & 12 \\
4 & 60 & 5 & 16 \\
\hline
\end{tabular}




\subsection{Caracterization of DXSL-I}

\subsubsection{Elemental Analysis}

The results of element analysis of CP, CHPTAC and cationic modified flocculants DXSL-I are shown in Table 2. It has been found that corncob does not show any significant presence of nitrogen. And the negligible amount of nitrogen was $0.2 \%$ in CP is because of the presence of trace quantities of proteins in the corncob powder. It is shown in Table 1 that there is a considerable percentage of nitrogen in the flocculants DXSL-I, which can be accounted for the presence of CHPTAC chain onto the backbone of corncob. Evaluation of the synthesis reaction efficiency is based on the determination of nitrogen content in the modified flocculants according to elemental analysis. From the element analysis table, it appears that CHPTAC monomer are incorporated in greater extent with increase in its concentration, possibly through participation of larger number of $\mathrm{OH}$ groups of corncob in covalent linkages.

\subsubsection{FTIR Analysis}

The FTIR spectra of cationic flocculation DXSL-I, alkalized CP and CP were shown in Figures 2a-c, respectively.

The broad band (Figure 2a) at $3404 \mathrm{~cm}^{-1}$ is due to the stretching vibration of the $\mathrm{OH}$ groups. The band at 1635 $\mathrm{cm}^{-1}$ is for $\mathrm{OH}$ bending vibration. The bands at 1252 and $2925 \mathrm{~cm}^{-1}$ are assigned to $\mathrm{C}=\mathrm{O}$ stretching and $\mathrm{CH}$ stretching, respectively. The bands at $1431 \mathrm{~cm}^{-1}$ are due to $\mathrm{CH}$ bending vibration. The two bands at $1051 \mathrm{~cm}^{-1}$ and $1512 \mathrm{~cm}^{-1}$ are attributed to $\mathrm{CH}_{2}-\mathrm{O}-\mathrm{CH}_{2}$ and epoxy groups stretching vibrations. Figure $\mathbf{2 b}$ shows the FTIR spectra of alkalized CP. The broad peak at $3397 \mathrm{~cm}^{-1}$ is due to the $\mathrm{OH}$ stretching vibration. The intensive band at 2915 $\mathrm{cm}^{-1}$ is due to $\mathrm{CH}$ stretching vibration. Two bands at 1051 and $1512 \mathrm{~cm}^{-1}$ are for $\mathrm{CH}_{2}-\mathrm{O}-\mathrm{CH}_{2}$ and epoxy groups stretching vibrations, respectively. It is found that the band at $1251 \mathrm{~cm}^{-1}$ was not present in Figure 2b, which indicate synthesis reactions in Eqs. 2 and $\mathbf{3}$ have happened. The broad band (Figure 2c) at $3409 \mathrm{~cm}^{-1}$ is due to the stretching vibration of the $\mathrm{OH}$ groups. The presence of an additional band at $1395 \mathrm{~cm}^{-1}$ in Figure 2c due to the CN stretching vibration is a clear proof of incorporation of cationic monomer onto the backbone of CP.

\subsubsection{SEM Analysis}

Figures 3-5 show the scanning electron micrographs

Table 2. Results of Elemental Analysis.

\begin{tabular}{cccc}
\hline Polymer & $\% \mathrm{C}$ & $\% \mathrm{H}$ & $\% \mathrm{~N}$ \\
\hline CP & 36.5 & 6.4 & 0.2 \\
CHPTAC & 37.8 & 7.8 & 7.2 \\
DXSL-I & 37.2 & 6.1 & 3.5 \\
\hline
\end{tabular}

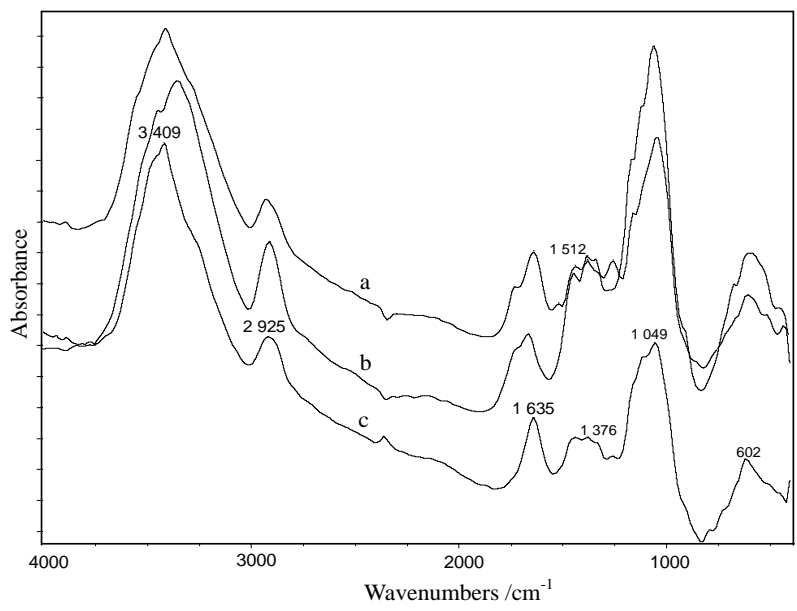

Figure 2. IR spectra of (a) CP, (b) alkalized CP and (c) DXSL-I.

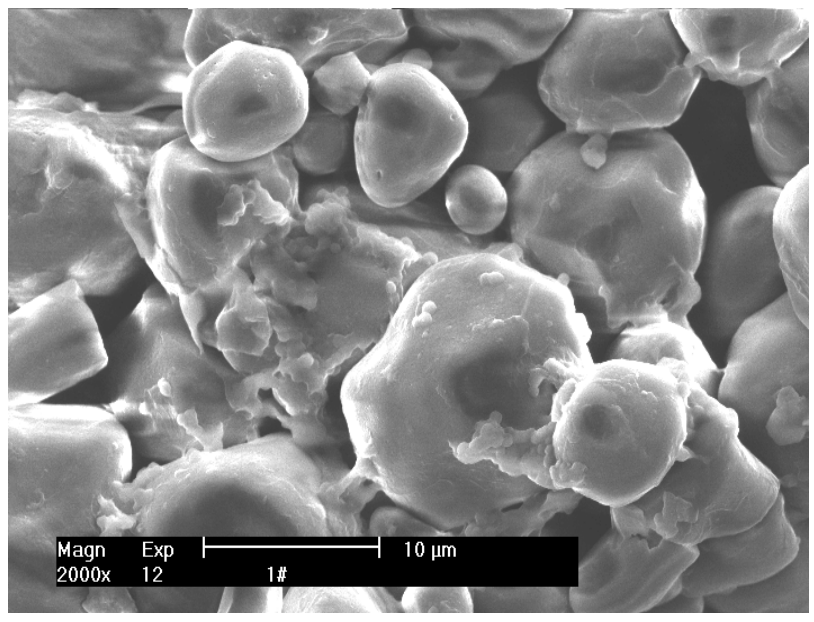

Figure 3. SEM micrograph of CP.

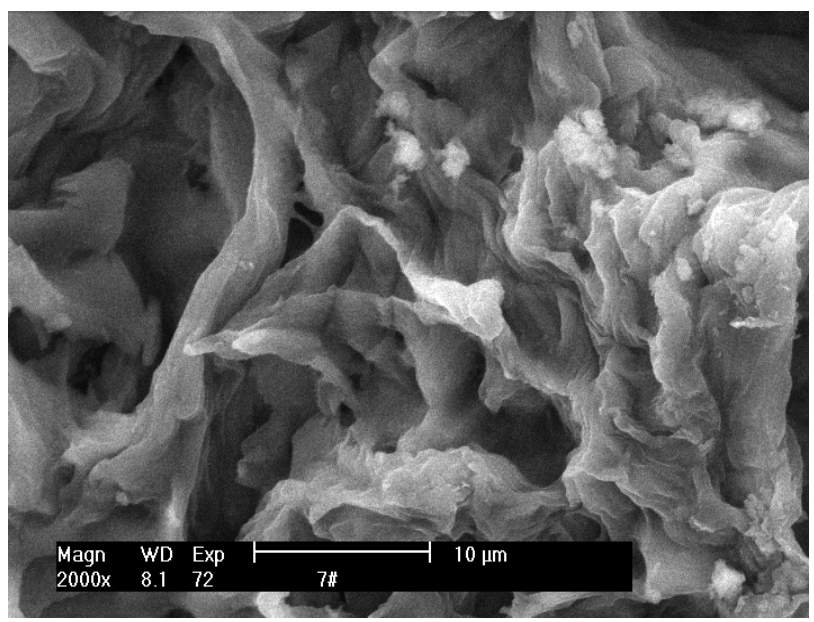

Figure 4. SEM micrograph of alkalized CP.

of CP, alkalized CP and DXSL-I, respectively. A careful examination of the micrographs reveals a difference in the morphological appearance of the polymers. CP has a granular structure, which changed drastically when it was 


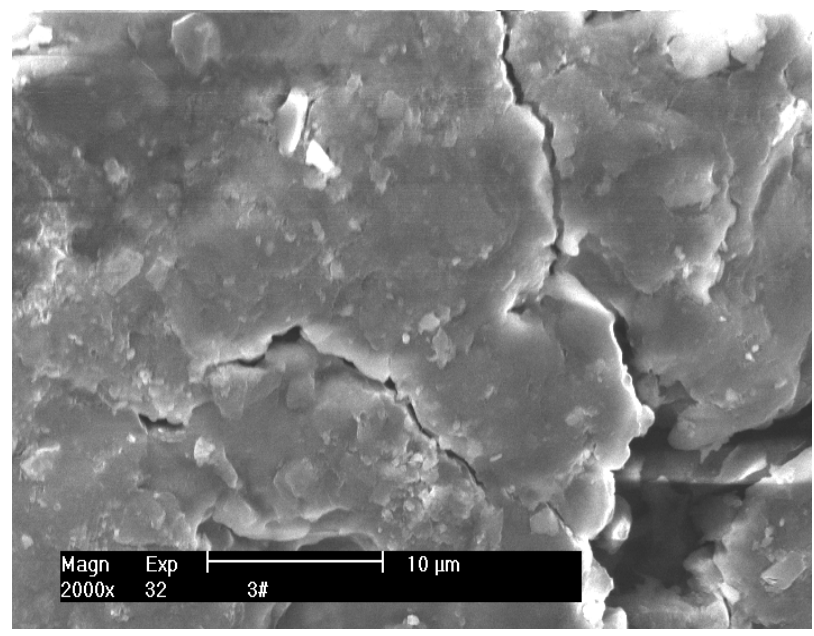

Figure 5. SEM micrograph of DXSL-I.

alkalized and grafted with cationic etherifying monomer CHPTAC. The appearance of Alkalized CP seems incompact, which is helpful for $\mathrm{OH}$ groups exposed and grafting reaction. However, DXSL-I appeared embedded structure. It can be explained that the alkalized CP combined with etherifying monomers formed a kind of structure mingling soft and rigid property. This observation also supported the grafting of CHPTAC onto the backbone of CP.

\subsection{Flocculation Characteristic}

An attempt has been made to compare the flocculation characteristics of DXSL-I with some of the commercially available flocculants in $0.25 \%$ (w/v) kaolin suspensions (Figure 6). The characteristics made it appropriate for treating wastewater with a high efficiency in a wide $\mathrm{pH}$ range without $\mathrm{pH}$ adjustment. It can be concluded that DXSL-I has the similar capacity to polyacrylamide, but superior to aluminum chloride. Its performance is better than that of other commercial flocculants because the kaolin particles have high negative charges and in this case, it appears that the cationic along with easy approachability of branched structure of CHPTAC dominates the performance.

\section{CONCLUSION}

From the above results, it can be concluded that cationic monomer CHPTAC is grafted onto the backbone of CP. Variation in the synthetic parameters results in different flocculation efficiency. Investigation of elemental analysis, FTIR spectra and SEM provide a strong proof of cationization. In comparison with the commercial flocculants, the best performing of the cationic modified flocculants DXSL-I having long CHPTAC chains show better flocculation characteristics.

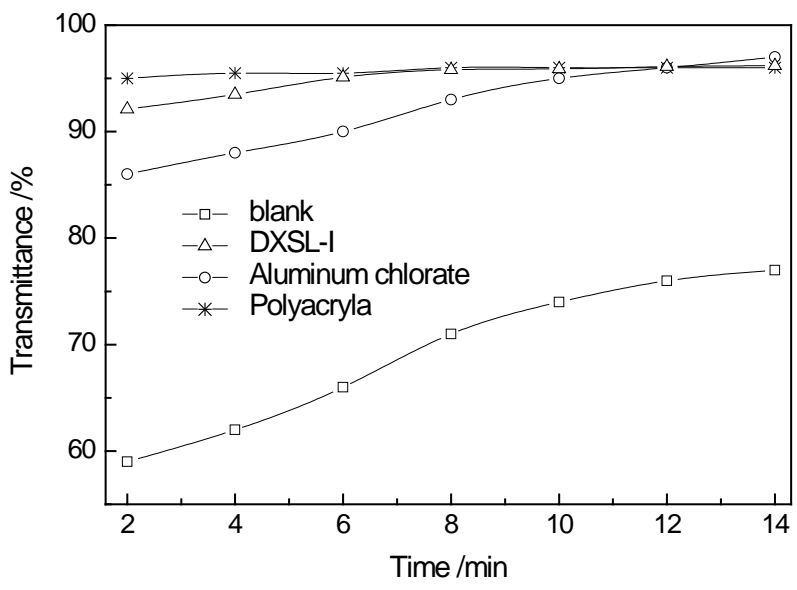

Figure 6. Flocculation performance in Kaolin suspensions.

\section{ACKNOWLEDGEMENTS}

The authors thank the Dalian Maritime University Research Fund for its support of this research.

\section{REFERENCES}

[1] Bratby, J. (1980) Coagulation and flocculation. Uplands Press, London.

[2] Gregory, J. (1981) Chemistry and technology of water soluble polymers. Plenum Press, New York.

[3] Aguilar, M.I., Sáez J., Lloréns, M., Soler, A., Ortuño, J.F., Meseguer, V. and Fuentes, A. (2005) Improvement of coagulation-flocculation process using anionic polyacrylamide as coagulant aid. Chemosphere, 58, 47-56. http://dx.doi.org/10.1016/j.chemosphere.2004.09.008

[4] Ibrahim, S.S. and Abdel-khalek, N.A. (1992) The action of different types of corn starch on the flocculation of phosphate slimes. Minerals Engineering, 5, 907-916. http://dx.doi.org/10.1016/0892-6875(92)90257-A

[5] Böhm, N. and Kulicke, W.M. (1997) Optimization of the use of polyelectrolytes for dewatering industrial sludges of various origins. Colloid and Polymer Science, 275, 7381. http://dx.doi.org/10.1007/s003960050054

[6] Bolto, B.A. (1995) Soluble polymer in water purification. Progress in Polymer Science, 20, 987-1041. http://dx.doi.org/10.1016/0079-6700(95)00010-D

[7] Yang, W.Y., Qian, J.W. and Shen, Z.Q. (2004) A novel flocculant of $\mathrm{Al}(\mathrm{OH})_{3}$-polyacrylamide ionic hybrid. Journal of Colloid and Interface Science, 273, 400-405. http://dx.doi.org/10.1016/j.jcis.2004.02.002

[8] Schintu, M., Meloni, P. and Contu, A. (2000) Aluminum fractions in drinking water from reservoirs. Ecotoxicology and Environment Safety, 46, 29-33. http://dx.doi.org/10.1006/eesa.1999.1887

[9] Rath, S.K. and Singh, R.P. (1998) Grafted amylopectin: applications in flocculation. Colloids Surface A, 139, 129-135. http://dx.doi.org/10.1016/S0927-7757(98)00250-7

[10] Tripathy, T. and Singh, R.P. (2000) High performance 
flocculating agent based on partially hydrolysed sodium alginate-g-polyacrylamide. European Polymer Journal, 36, 1471-1476. http://dx.doi.org/10.1016/S0014-3057(99)00201-3

[11] Mishra, A., Srinivasan, R., Bajpai, M. and Dubey, R. (2004) Use of polyacrylamide-grafted plantago psyllium mucilage as a flocculant for treatment of textile wastewater. Colloid and Polymer Science, 282, 722-727. http://dx.doi.org/10.1007/s00396-003-1003-1

[12] Burr, R.C., Fanta, G.F., Doane, W.M. and Russel, C.R. (1975) Starch graft copolymers for water treatment. Starch, 27, 155-159. http://dx.doi.org/10.1002/star.19750270504

[13] Khalil, M.I. and Aly, A.A. (2002) Preparation and evaluation of some anionic starch derivatives as flocculants. Starch-Starke, 54, 132-139. http://dx.doi.org/10.1002/1521-379X(200204)54:3/4<132 ::AID-STAR132>3.0.CO;2-E

[14] Larsson, A. and Wall, S. (1998) Flocculation of cationic amylopectin starch and colloidal silicic acid. The effect of various kinds of salt. Colloids Surface A, 139, 259-270. http://dx.doi.org/10.1016/S0927-7757(98)00326-4

[15] Choong, J., Young, J.Y. and Wolfgang, H.H. (2005) Environmental effects and desorption characteristics on heavy metal removal using carboxylated alginic acid. Bioresource Technology, 96, 15-19. http://dx.doi.org/10.1016/j.biortech.2004.03.001
[16] Nayak, B.R. and Singh, R.P. (2001) Development of graft copolymer flocculating agents based on hydroxypropyl guar gum and acrylamide. Journal of Applied Polymer Science, 81, 1776-1785.

http://dx.doi.org/10.1002/app.1610

[17] Ellis, H.A., Utah, S.I., Ogunrinde, A. and Ogedengbe, M.O. (1982) Preparation of some cationic starches as flocculants for water. Water Research, 16, 1433-1435. http://dx.doi.org/10.1016/0043-1354(82)90231-7

[18] Sheng, X.Q., Ding, Y.S. and Gong, W.M. (2002) Preparation and evaluation of cationic natural polymer flocculant. Journal of Dalian Maritime University, 28, 72-75. (in Chinese)

[19] Lv, X.X., Li, H.Y. and Huang, K.Y. (2004) Effect of different pretreatment methods on constituents of corn-cob. Journal of Chemical Industry of Forest Products, 2, 1113. (in Chinese)

[20] Ren, J.L., Sun, R.C., Liu, C.F., Chao, Z.Y. and Luo, W. (2006) Two-step preparation and thermal characterization of cationic 2-hydroxypropyltrimethylammonium chloride hemicellulose polymers from sugarcane bagasse. Polymer Degradation and Stability, 91, 2579-2587. http://dx.doi.org/10.1016/j.polymdegradstab.2006.05.008

[21] Ju, B.Z., Zhang, S.F. and Yang, J.Z. (2001) Progress in preparation of cationic starch using the dry process. Fine Chemicals, 18, 46-49. (in Chinese) 